\title{
The Role of Lysobacter antibioticus HS124 on the Control of Fall Webworm (Hyphantria cunea Drury) and Growth Promotion of Canadian Poplar (Populus canadensis Moench) at Saemangeum Reclaimed Land in Korea
}

\author{
Jae-Hyun Moon ${ }^{1}$, Sang-Jae Won ${ }^{1}$, Chaw Ei Htwe Maung ${ }^{2}$, Jae-Hyeok Choi ${ }^{1}$, Su-In Choi ${ }^{1}$, Henry B. Ajuna ${ }^{1}$, \\ Young Sang Ahn $1, * \mathbb{C}$ and Yong Hun Jo ${ }^{3, * \mathbb{C}}$
}

1 Department of Forest Resources, College of Agriculture and Life Sciences, Chonnam National University, Gwangju 61186, Korea; mjh132577@naver.com (J.-H.M.); lazyno@naver.com (S.-J.W.); cjh960728@gmail.com (J.-H.C.); suin917@naver.com (S.-I.C.); ajunahenry@mmu.ac.ug (H.B.A.)

2 Division of Agricultural and Biological Chemistry, Institute of Environmentally Friendly Agriculture, College of Agriculture and Life Sciences, Chonnam National University, Gwangju 61186, Korea; chaweihtwemaung@gmail.com

3 Department of Applied Biology, Institute of Environmentally Friendly Agriculture, College of Agriculture and Life Sciences, Chonnam National University, Gwangju 61186, Korea

check for updates

Citation: Moon, J.-H.; Won, S.J.; Maung, C.E.H.; Choi, J.-H.; Choi, S.-I.; Ajuna, H.B.; Ahn, Y.S.; Jo, Y.H. The Role of Lysobacter antibioticus HS124 on the Control of Fall Webworm (Hyphantria cunea Drury) and Growth Promotion of Canadian Poplar (Populus canadensis Moench) at Saemangeum Reclaimed Land in Korea. Microorganisms 2021, 9, 1580. https://doi.org/10.3390/

microorganisms 9081580

Academic Editor: Michael J. Bidochka

Received: 8 June 2021

Accepted: 21 July 2021

Published: 25 July 2021

Publisher's Note: MDPI stays neutral with regard to jurisdictional claims in published maps and institutional affiliations.

Copyright: (c) 2021 by the authors. Licensee MDPI, Basel, Switzerland. This article is an open access article distributed under the terms and conditions of the Creative Commons Attribution (CC BY) license (https:// creativecommons.org/licenses/by/ $4.0 /)$.
* Correspondence: ysahn@jnu.ac.kr (Y.S.A.); yhun1228@jnu.ac.kr (Y.H.J.); Tel.: +82-62-530-2081 (Y.S.A.); Fax: +82-62-530-2089 (Y.S.A.)

\begin{abstract}
Populus canadensis Moench forests established in Saemangeum-reclaimed land have been invaded by Hyphantria cunea Drury, causing defoliation and stunted growth. This study investigated the biocontrol potential of cuticle degrading chitinase and protease secreted by Lysobacter antibioticus HS124 against H. cunea larvae. In addition, L. antibioticus HS124 was examined for indole-3-acetic acid phytohormone production for plant growth promotion. To determine the larvicidal activity in the laboratory experiments, crude enzymes, bacteria culture, CY medium, and water (control) were sprayed on the larvae reared on natural diet in insect rearing dishes. Treatment with crude enzymes and bacteria culture caused $76.7 \%$ and $66.7 \%$ larvae mortality, respectively. The larvae cuticle, mainly composed of chitin and proteins, was degraded by cuticle-degrading enzymes, chitinase, and protease in both the bacteria culture and crude enzyme treatments, causing swelling and disintegration of the cuticle. Field application of the bacteria culture was achieved by vehicle-mounted sprayer. Bacterial treatment caused morphological damage on the larvae cuticles and subsequent mortality. Foliar application of the bacteria culture reduced tree defoliation by H. cunea and enhanced growth compared to the control. Especially, L. antibioticus HS124 produced auxins, and increased growth of poplar trees.
\end{abstract}

Keywords: entomopathogenic bacteria; cuticle degrading enzymes; forest pests; auxin; plant development; poplar biomass

\section{Introduction}

Global demand to produce fast-growing forest trees has progressively increased in recent years because of the impact on global climate and concerns about energy security $[1,2]$. Plantations of woody species with fast growth rates and short cultivation periods are a desirable source of renewable energy [3]. Populus, or poplars, are a genus of deciduous trees in the family Salicaceae with more than 30 species grown in Asia, Europe, Africa, and America [4,5]. These species are well known for their adaptability to unfavorable environments, including low fertility and high saline soils [4-6]. Among the Populus species, Populus canadensis Moench, a natural hybrid of Populus deltoides Marsh and Populus nigra var. italica, is a key species in forest tree plantations in temperate regions, accounting for 
over $90 \%$ of cultivated poplars globally [4]. In the late 19th century, the Korean government constructed Saemangeum-reclaimed land to increase the cultivatable cropland, in response to limited agricultural plains [7-9]. However, due to high soil salinity variations, salt tolerant species such as $P$. canadensis have been established for bioenergy production and carbon sequestration $[9,10]$. However, P. canadensis are highly vulnerable to fall webworm (Hyphantria cunea Drury) invasion (Figure 1C). The larvae of H. cunea are gregarious polyphagous pests that cause extensive forest defoliation and form innumerable webbings, which reduce the photosynthetic efficiency, leading to stunted growth and subsequent decrease in biomass production. H. cunea (Lepidoptera: Erebidae) is a native of North America, from where it accidentally spread to various parts of Europe and Asia [11]. The global warming phenomenon has significantly increased the density of H. cunea, which occurs mainly in warmer regions [12-14]. These larvae are known to infest and feed a broad host range with over 600 plant species including forest trees, fruit trees, and herbaceous and agricultural crops from late summer to early fall [11]. Even though trees can survive extensive defoliation, the loss of leaves reduces the rate of photosynthesis and leads to stunted tree growth [5]. Moreover, severe defoliation increases susceptibility and transmissibility of phytopathogens, resulting in tree mortality, longer rotation periods, and significant economic losses in commercial tree production [5].

A

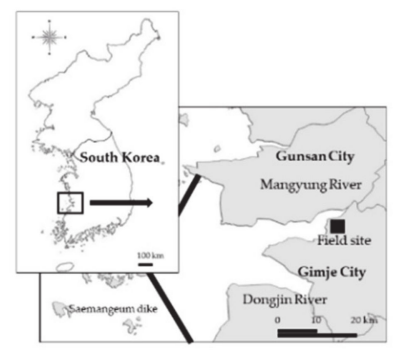

B (a)

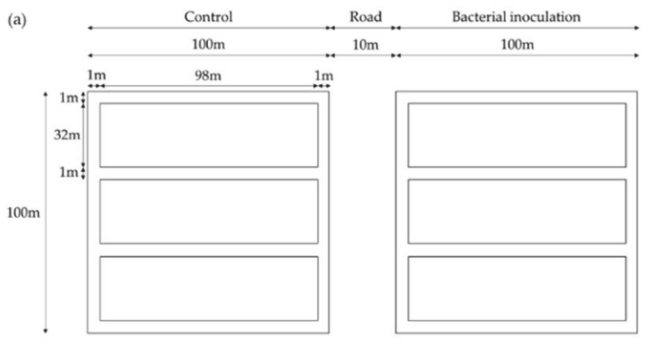

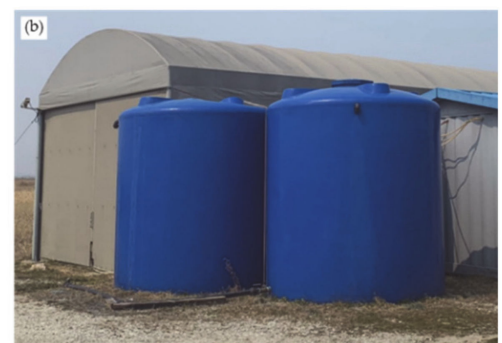

C

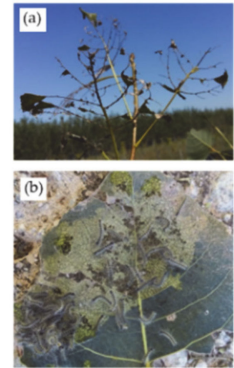

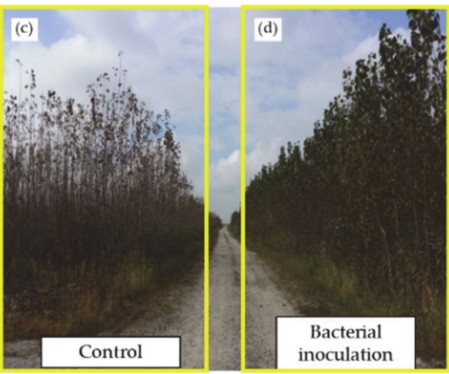

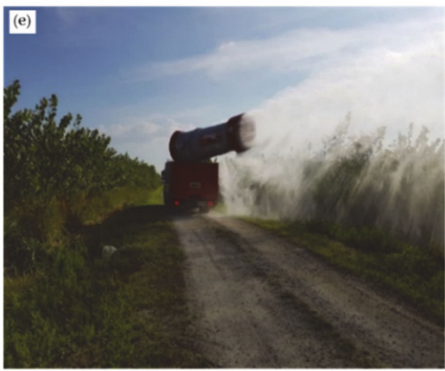

Figure 1. Locations of Saemangeum-reclaimed land (A). Illustration of field experimental site with the control and bacterial inoculation treatment plots (Ba) and on-farm large-scale cultivation of Lysobacter antibioticus HS124 in fermentation tank $(\mathrm{Bb})$. Tree defoliation by Hyphantria cunea larvae in the control group $(\mathbf{C a}-\mathbf{C c})$ and Populus canadensis vegetation in the treatment group and foliar application of bacterial using a vehicle-mounted sprayer $(\mathbf{C d}-\mathbf{C e})$.

Generally, chemical pesticides are extensively used to reduce pest invasions due to quick and consistent action. However, frequent use of synthetic pesticides poses serious problems, such as pesticide resistance, alteration in soil microbial diversity, and contamination of water, air, and soil ecosystem [15-17], in forest management. In addition, only about $0.1 \%$ of the applied pesticides reach the targeted organisms, while the remaining bulk escapes to the environment and adversely affects non-target beneficial organisms such as natural enemies, pollinators, and earthworms [15-17]. Thus, many researchers and non-governmental organizations have expressed concerns about environmental pollution from leached chemicals in the Saemangeum-reclaimed land. Consequently, the Korean government enacted a law prohibiting the use of chemical products in the Saemangeumreclaimed land $[7,8]$. Therefore, the Korean forest services (KFS) cannot use pesticides in Saemangeum-reclaimed land, and there is a need to develop environmentally friendly 
techniques for controlling H. cunea and increase biomass production of P. canadensis plantations. Several pest management strategies, including the use of larvicidal plant extracts, sex pheromones, entomopathogens, and natural enemies, such as predators and parasitoids, have been employed in the management of various pests $[11,18]$. The use of natural enemies plays a major role in maintaining the pest population below the threshold level, but appropriate technologies for mass rearing and strategic release are still challenging [11,19]. The application of entomopathogenic bacteria, also known as biocontrol agents, has become increasingly attractive as eco-friendly alternatives to chemical pesticides $[18,20,21]$. Entomopathogenic bacteria have high specificity to target pests and are not harmful to humans, wild animals, and other organisms, including natural enemies [22]. However, the application of biocontrol agents on large-scale forest areas has been challenged by unfavorable environmental conditions (such as cold weather and dry conditions) which reduce the performance of entomopathogens and lower production efficiency [11,21].

The most widely used microbial pesticides are based on entomopathogenic bacterium, Bacillus thuringiensis (Bt) [20]. However, the long-term use of $\mathrm{Bt}$ as a classical biological control strategy has resulted in Bt toxin resistance in various orders of insect pests, including Lepidoptera, Coleoptera, and Diptera [23]. Therefore, there is an urgent need to develop additional microbial agents to control the growing pest population. Entomopathogenic bacteria interfere with the growth and survival of the insect pest through the production of diverse active metabolites, including toxins and cuticle degrading enzymes [18,20]. In particular, cuticle-degrading enzymes, such as chitinases and proteases produced by entomopathogenic bacteria, play a key role in breaking down the cuticles of insect pests, which are mainly composed of chitin and protein [20,21,24,25]. Cuticular chitin and cuticular protein are vital components of insect cuticles, but are also an easy target in insect pest management [25-27]. Chitinases are among the most valuable hydrolytic enzymes deployed by entomopathogenic bacteria to degrade vital structures of insect pests, such as the cuticle in the exoskeleton [28]. In addition, proteases have hydrolytic activity on various proteins present in the larvae cuticle which could cause decomposition of the insect pest exoskeleton $[26,29]$. Decomposed cuticles cause protective barriers to rupture which consequently leads to insect mortality [21]. Additionally, some bacteria play a vital role as biofertilizers, providing plants with phytohormones, such as auxin, which promote plant growth [7,8,30-32]. Phytohormone auxin improves plant growth by stimulating a wide range of processes, including cell division, tissue growth, and lateral root initiation [30,33]. Specifically, Lysobacter antibioticus strains have been reported to exhibit a pronounced inhibitory effect against insect pests [34] and the potential to promote biomass production through auxin production [31]. However, the simultaneous pesticidal effects and the promotion of biomass yield in bioenergy-producing trees has not been reported under field conditions. The cultivation of $P$. canadensis on Saemangeum-reclaimed land in Korea is constrained by limited knowledge regarding the management of H. cunea using ecofriendly methods. Therefore, the objective of this study was to investigate the biocontrol potential of L. antibioticus HS124 against the H. cunea larvae and increasing biomass yield of $P$. canadensis in the Saemangeum-reclaimed land. Treatment with entomopathogenic bacteria, L. antibioticus HS124, caused larvae mortality, prevented defoliation, and improved the growth of $P$. canadensis and can thus serve as an alternative to chemical use for simultaneous control of H. cunea larvae and for enhancing biomass production in the field.

\section{Materials and Methods}

\subsection{Study Area Description}

The study was conducted in Saemangeum-reclaimed land, in an estuary tidal flat that lays at the intersection of the Mangyung and Dongjin Rivers in the southwest coastal region of Korea (Figure 1A). This area is approximately 40,000 ha and is therefore one of the largest land reclamation projects in Korean history. The reclaimed land was not provided with landfill for soil improvements. The soils in the study area were mainly fluvial-marine deposits and the dominant soil is sandy loam, with a slope of 0 to $2 \%$. High salinity and 
low soil fertility are the primary constraints limiting plant growth and land development in this region [6-10]. Reeds (Phragmites communis Trinius) are the dominant vegetation, while most woody plants barely grow in the area due to salt stress. The study area has a temperate climate with an annual mean temperature of $13.0^{\circ} \mathrm{C}$ [14]. The mean annual precipitation on-site is about $1233.4 \mathrm{~mm}$, with approximately $51.3 \%$ falling between June and August over the last 10 years [14].

Since 2012, the KFS has established 180 ha of P. canadensis plantations in the study area to produce wood pellets for bioenergy production. The experimental site $\left(35^{\circ} 52^{\prime} 14^{\prime \prime} \mathrm{N}\right.$ latitude, $126^{\circ} 46^{\prime} 2^{\prime \prime}$ E longitude) was approximately 2 ha, planted at a density of 8000 cuttings per hectare (at a spacing of $1.25 \mathrm{~m} \times 1.25 \mathrm{~m}$ ). The experimental site was divided into two blocks of 1 ha each with a roadway of $10 \mathrm{~m}$ width running in between (Figure 1B). Each block was divided into 3 separate plots $(98 \mathrm{~m} \times 32 \mathrm{~m}$ each) and the plots were separated by a water channel of $1 \mathrm{~m}$ width and $1 \mathrm{~m}$ deep. (1) One block containing three plots (replicates) was allocated for L. antibioticus HS124 culture treatment and (2) the other block containing three replicates was assigned to the control group (without water and bacterial culture). The cuttings (approximately $100 \mathrm{~cm}$ high and $1 \mathrm{~cm}$ in diameter) were plant in the experiment plots in 2013. By 2015, the established trees were approximately $4.0 \mathrm{~m}$ high, with a root collar diameter of $4 \mathrm{~cm}$, distributed uniformly in the experiment plots. However, in 2015, severe infestation by H. cunea larvae caused extensive defoliation of $P$. canadensis trees, creating innumerable webbed nests over the canopy, which reduced photosynthetic efficiency and subsequently decreased biomass yields (Figure 1).

\subsection{Bacterial Culture and Growth Conditions}

The bacterial strain L. antibioticus HS124 was isolated from pepper field soils in Naju City, Korea [34]. Then, L. antibioticus HS124 was streaked on casitone-yeast extract agar (CYA) medium (bacto-casitone $3 \mathrm{~g}, \mathrm{CaCl}_{2} \cdot 2 \mathrm{H}_{2} \mathrm{O} 1.36 \mathrm{~g}$, yeast extract $1 \mathrm{~g}$ and agar $20 \mathrm{~g}$ in $1 \mathrm{~L}$ distilled water) and inoculated at $30^{\circ} \mathrm{C}$ for 3 days. To examine growth conditions and the cuticle-degrading enzyme (chitinase and protease) activity of L. antibioticus HS124, 10 colonies were pre-inoculated in casitone-yeast extract (CY) broth at $30^{\circ} \mathrm{C}$ and $120 \mathrm{rpm}$ in a shaking incubator (H1012 Incu-Shaker, Benchmark Scientific Inc., Edison, NJ, USA) for 3 days [31]. Then, $200 \mu \mathrm{L}$ of the bacterial culture $\left(10^{5}\right.$ cells $\left./ \mathrm{mL}\right)$ was inoculated again in $200 \mathrm{~mL}$ of CY medium containing $1 \%$ chitin powder. The experiment was conducted in three replicates and the flasks were incubated at $30^{\circ} \mathrm{C}$ in a shaking incubator at $120 \mathrm{rpm}$ for 10 days. Samples were collected daily for 10 days. Then, the samples were serially diluted and spread on the CYA medium. The plates were incubated at $30^{\circ} \mathrm{C}$ for 3 days. Bacteria cells release extracellular metabolites such as hydrolytic enzymes during growth and thus cell growth can be used to predict the point of maximum efficacy of the bacteria culture for field application [32]. The number of cells on CYA medium were counted each incubation day to determine the growth pattern of L. antibioticus HS124.

\subsection{Production of Cuticle Degrading Enzymes by Lysobacter antibioticus HS124}

To examine the chitinase- and protease-producing activity of L. antibioticus HS124 during the incubation period, bacteria cultures were collected daily for 10 days and kept at $-70{ }^{\circ} \mathrm{C}$ until analyzed. The cultures were thawed and centrifuged at $12,000 \mathrm{rpm}$ for $10 \mathrm{~min}$ in a centrifuge machine (Combi R515, Hanil Scientific Inc., Seoul, Korea). The supernatants were used to analyze chitinase and protease activity. Chitinase activity was measured as previously described [35]. Reaction mixtures were prepared in Eppendorf tubes by mixing $50 \mu \mathrm{L}$ of bacterial supernatant, $450 \mu \mathrm{L}$ of $50 \mathrm{mM}$ sodium acetate buffer (pH 5.0), and $500 \mu \mathrm{L}$ of $0.5 \%$ colloidal chitin solution. The tubes were then incubated at $37^{\circ} \mathrm{C}$ for $1 \mathrm{~h}$. To end the reaction, $200 \mu \mathrm{L}$ of $1 \mathrm{~N} \mathrm{NaOH}$ was added and the tubes were centrifuged at 12,000 rpm for $7 \mathrm{~min}$ at $4{ }^{\circ} \mathrm{C}$. Then, $750 \mu \mathrm{L}$ of the supernatant was mixed with $1 \mathrm{~mL}$ of Schales' reagent and $250 \mu \mathrm{L}$ of distilled water and the mixture boiled $100{ }^{\circ} \mathrm{C}$ for $15 \mathrm{~min}$. The amount of reducing sugar was determined using a UV spectrophotometer (UV-1650PC, Shimadzu, 
Kyoto, Japan) at an absorbance of $420 \mathrm{~nm}$. One unit of chitinase activity was defined as the reducing activity that released $1 \mu \mathrm{mol}$ of $\mathrm{N}$-acetyl-glucosamine per $\mathrm{h}$ at $37^{\circ} \mathrm{C}$.

Protease activity was determined following a preexisting method [36] wherein tris buffer $(100 \mathrm{mM})$ containing $2 \mathrm{mM} \mathrm{CaCl}_{2}$ and $1 \%$ casein was prepared and adjusted to $\mathrm{pH}$ 8.0. A reaction mixture containing $50 \mu \mathrm{L}$ of bacterial supernatant and $950 \mu \mathrm{L}$ of tris buffer was incubated at $60{ }^{\circ} \mathrm{C}$ for $15 \mathrm{~min}$. Then, $500 \mu \mathrm{L}$ of $20 \%$ trichloroacetic acid was added to terminate the reaction. The mixture was centrifuged at 13,000 rpm for $15 \mathrm{~min}$ and absorbance of the supernatant containing acid-soluble proteins was measured at $280 \mathrm{~nm}$ using a UV spectrophotometer. One unit of protease activity was defined as the amount of enzyme that liberated $1 \mu \mathrm{g}$ of tyrosine per min.

\subsection{Identification of Chitinase and Protease Genes from the Lysobacter antibioticus HS124 Genome}

The bioinformatic data lays a strong foundation for obtaining in-depth knowledge about hydrolytic enzymes deployed by entomopathogenic L. antibioticus HS124. A localblast database was constructed using the makeblastdb program with the L. antibioticus HS124 genome (CAQP01.1.fsa_nt) obtained from GenBank (https: / / www.ncbi.nlm.nih. gov/ (accessed on 3 July 2020)). Then, chitinase and protease genes were identified by local-tblastn analysis with Lysobacter chitinase and protease protein sequences obtained from GenBank (Tables S1 and S2) as a query for L. antibioticus HS124 genome database. Identified chitinase and protease genes were confirmed by blastp analysis (https:/ / blast.ncbi.nlm.nih.gov / Blast.cgi (accessed on 3 July 2020)) with the nr database. Additionally, the signal peptide domain of these genes was predicted by the SignalP-5.0 program (http: / / www.cbs.dtu.dk/services/SignalP/ (accessed on 3 July 2020)).

\subsection{Preparation of Bacterial Culture and Crude Enzymes from Lysobacter antibioticus HS124}

To obtain the bacterial culture and crude enzymes for assessing L. antibioticus HS124 larvicidal activity against the H. cunea larvae, the bacteria colony was inoculated into $5 \mathrm{~L}$ of CY medium containing $1 \%$ chitin powder and incubated at $30{ }^{\circ} \mathrm{C}$ and $120 \mathrm{rpm}$ on a shaking incubator for 7 days. Then, $1 \mathrm{~L}$ of the bacterial culture was maintained at $4{ }^{\circ} \mathrm{C}$ for the larvicidal activity experiment. The remaining $4 \mathrm{~L}$ of bacterial culture was centrifuged at $6000 \mathrm{rpm}$ for $30 \mathrm{~min}$ and the supernatant was filtered through four layers of filter paper (Whatman No.6, Whatman International Ltd., Maidstone, England). The filtered supernatant was precipitated with $80 \%$ ammonium sulfate by gently stirring at $4{ }^{\circ} \mathrm{C}$. Then, the solution was maintained overnight at $4{ }^{\circ} \mathrm{C}$ to enhance protein precipitation and stabilization. The precipitated crude enzymes were collected from the mixture by centrifugation at $6000 \mathrm{rpm}$ for $30 \mathrm{~min}$ and the pellet containing crude enzymes was dissolved in a small amount of $50 \mathrm{mM}$ potassium phosphate buffer $(\mathrm{pH}$ 6.0). Then, the crude enzymes were kept in a dialysis tube and dialyzed against the same buffer at $4^{\circ} \mathrm{C}$ for $24 \mathrm{~h}$ in a refrigerator. The total protein concentration of crude enzymes was determined using bovine serum albumin as the standard [37]. The crude enzymes were maintained at $-70{ }^{\circ} \mathrm{C}$ for the larvicidal activity experiment against the $H$. cunea larvae.

\subsection{Larvicidal Activity of Lysobacter antibioticus HS124 against the Hyphantria cunea Larvae}

To examine the larvicidal activity of L. antibioticus HS124 against the H. cunea larvae, four treatments, including a control (distilled water), the CY medium, bacterial culture, and bacterial crude enzymes, were tested in the laboratory. The CY medium and bacterial culture were diluted with water $(1: 2 v / v)$ to maintain uniformity with the concentration of L. antibioticus HS124 cultures used in the field experiments. CY medium was used as a control for L. antibioticus HS124 bacteria culture, which was prepared in the same media. The CY medium application rate was based on the basal CY medium application rate for the $L$. antibioticus HS124 culture.

In July $2019, H$. cunea larvae $(0.6-0.8 \mathrm{~cm})$ were collected from the leaves of $P$. canadensis from an untreated field in the study area. The larvae were maintained in an insect rearing cage (55 cm width $\times 35 \mathrm{~cm}$ length $\times 40 \mathrm{~cm}$ depth) at $25 \pm 2{ }^{\circ} \mathrm{C}$ and $75 \pm 10 \%$ relative 
humidity under natural light/dark conditions (14 h light/10 h dark). Larvae were reared under the above conditions for 1 week and fresh $P$. canadensis leaves were supplied twice. For the laboratory bioassay, P. canadensis leaves were collected from 2-year-old cuttings in a greenhouse with an automatic spray irrigation system at the forest nursery of the Chonnam National University. The leaves were cut to the same size $(8 \mathrm{~cm}$ wide $\times 8 \mathrm{~cm}$ long $)$ and cleaned with distilled water three times to remove other substances adhered to the leaves. The leaves were then air-dried at room temperature (approximately $25^{\circ} \mathrm{C}$ ) and one leaf was placed in each insect breeding Petri dish and 10 larvae were placed on each leaf.

For each treatment solution, $2 \mathrm{~mL}$ were sprayed on the larvae and leaf in each Petri dish and each treatment was conducted in three replicates. The dead larvae were counted daily for 10 days and the mortality rate (\%) was calculated based on the ratio of dead larvae to total larvae. The dead larvae in each treatment were preserved in separate sterile vials containing $4 \%$ paraformaldehyde solution and kept at $4{ }^{\circ} \mathrm{C}$ for scanning electron microscopy (SEM; GeminiSEM 500, Carl Zeiss AG, Oberkochen, Germany).

\subsection{Morphological Degradation of the Hyphantria cunea Larvae by Lysobacter antibioticus HS124}

To examine the effect of L. antibioticus HS124 on cuticle morphology of H. cunea larvae, the fixed samples were washed twice with phosphate-buffered saline ( $\mathrm{pH}$ 7.4). The samples were first dehydrated through a series of increasing alcohol concentration, i.e., 30, 50, 70, 80,95 , and $100 \%$ for 30 min each. Finally, the samples were dehydrated with isoamyl acetate for $1 \mathrm{~h}$ and air-dried under a fume hood overnight. The dried samples were coated with gold-nano particles at $60{ }^{\circ} \mathrm{C}$ and then observed on SEM at a magnification of $500 \times$ to investigate morphological degradation on the cuticle.

\subsection{Indole-3-Acetic Acid Production by Lysobacter antibioticus HS124}

Quantitative analysis of IAA production by L. antibioticus HS124 was performed using a UV spectrometric method as described previously [38]. Briefly, L. antibioticus HS124 was cultured in the CY medium containing L-tryptophan $(0.1 \mathrm{~g} / \mathrm{L})$. The culture was incubated at $30{ }^{\circ} \mathrm{C}$ in a shaking incubator $(140 \mathrm{rpm})$. Samples were taken every day for 10 days beginning on the day of inoculation. The samples were immediately centrifuged at $12,000 \mathrm{rpm}$ for $10 \mathrm{~min}$ at $4^{\circ} \mathrm{C}$ and $1 \mathrm{~mL}$ of the supernatant was mixed with $2 \mathrm{~mL}$ of Salkowski's reagent. Subsequently, the reaction mixture was incubated at room temperature in the dark for $25 \mathrm{~min}$. IAA concentration of each sample was measured at $530 \mathrm{~nm}$ using a UV spectrometer.

\subsection{Field Experimental Conditions and Plant Sampling}

The study was set up in two experimental groups, (1) control (without water and bacterial culture) and (2) L. antibioticus HS124 culture. Each group was divided into 3 plots (replicates) containing uniformly planted with P. canadensis trees. The L. antibioticus HS124 cultures were prepared in the CY medium. A liquid form of the microbial product containing $10^{10}$ cells/mL of L. antibioticus HS124 (GCM+, Purne, Jangseong, Korea) was used for large-scale cultivation of L. antibioticus HS124 at the field experimental site (Figure $1 \mathrm{~B}(\mathrm{~b})$ ). Typically, $300 \mathrm{~mL}$ of L. antibioticus HS124 liquid product was inoculated into $1000 \mathrm{~L}$ of $\mathrm{CY}$ medium and cultured at $30^{\circ} \mathrm{C}$ for 7 days using a fermenter (M-1000, MC Biotec, Gokseong, Korea). Then, L. antibioticus HS124 culture was diluted with tap water (1:2 v/v) and sprayed onto the leaves of $P$. canadensis trees. The incidence of H. cunea in Korea occurred from May to September 2016 and 2017. H. cunea is mainly bivoltine in South Korea. The eggs of the first-generation hatch in May and the last generation overwinter in September. Therefore, the treatments were applied at an interval of approximately 2-3 weeks, depending on weather conditions (carefully avoiding treatment wash-off or over-dilution by rainy weather). Therefore, a total of 5 and 6 applications of entomopathogenic L. antibioticus HS124 culture or water were done using a vehicle-mounted sprayer (HT-DV100, Zhengzhou Honest Machinery co., Ltd., Henan, China) from June to August in 2016 and 2017, respectively (Figure 1C). One week after every treatment application, 20 dead larvae 
were randomly collected from each plot and kept in $4 \%$ formaldehyde (fixating) solution to examine the morphological characteristics using SEM. Since the control group had no fatality, 20 living larvae were randomly picked and fixated for SEM morphological analysis.

To determine the effect of L. antibioticus HS124 culture treatment on tree growth (root collar diameter and height) and biomass production (leaf and stem dry weight), 20 trees were randomly harvested in October 2017. The diameter and lengths of shoot and root were measured using a centimeter $(\mathrm{cm})$ ruler. To determine the biomass, shoots and roots of each treatment were dried for $24 \mathrm{~h}$ in pre-weighed, moisture-free paper bag at $105^{\circ} \mathrm{C}$, in a convection drying oven (VS-1202D4, Vision Scientific, Daejeon, Korea) and the dry weight was measured $(\mathrm{kg})$ using electronic balance.

\subsection{Statistical Analysis}

Statistical analysis was conducted using statistical software (SPSS 25.0, SPSS Inc., Chicago, IL, USA). The data for cutting growth and biomass parameters were subjected to a $t$-test analysis, with significance level set at $\alpha=0.05$. The data of cell growth, cuticledegrading enzymes production, and IAA production were subjected to an analysis of variance (ANOVA) using Waller-Duncan test with a significance level set at $\alpha=0.05$. The larvae mortality data analyzed by two-way ANOVA, with the treatments and time postapplication as factors at $\alpha=0.05$. The results are reported as the mean \pm standard errors.

\section{Results}

3.1. Larvicidal Activity of Lysobacter antibioticus HS124 on the Hyphantria cunea Larvae 3.1.1. Growth Pattern of Lysobacter antibioticus HS124

The growth of L. antibioticus HS124 was low until 3 days after inoculation (Figure 2). Thereafter, growth of L. antibioticus HS124 rapidly increased until 6 days after inoculation, when the growth rate reached a maximum value of $4.6 \times 10^{7} \mathrm{cell} / \mathrm{mL}$. The growth of L. antibioticus HS124 sharply declined from 7 days post-inoculation until the end of the experimental period (Figure 2).

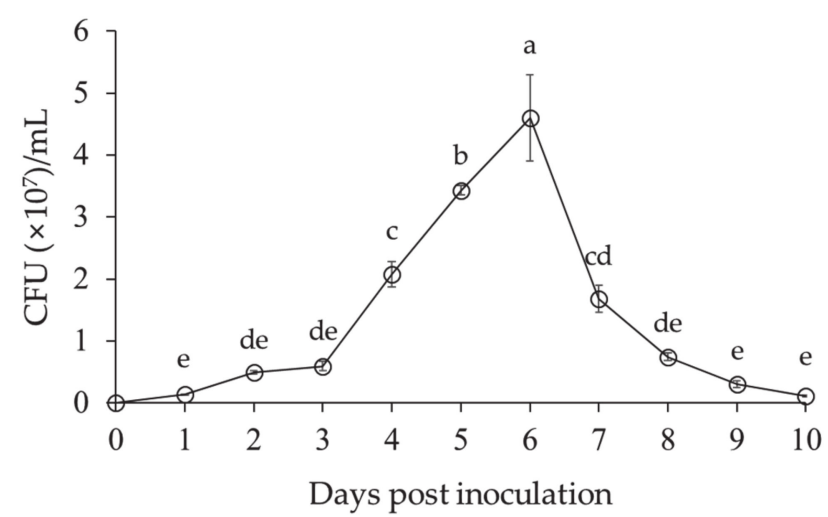

Figure 2. Cell growth curve of Lysobacter antibioticus HS124 in CY medium. Values are represented as means \pm standard errors $(n=3)$. Different superscripts in the figure indicate significantly different values using Waller-Duncan test $(p<0.05)$.

\subsubsection{Cuticle Degrading Enzymes Production by Lysobacter antibioticus HS124}

The chitinase activity of L. antibioticus HS124 was stable until 3 days after inoculation (Figure 3A). Thereafter, enzyme activity gradually increased from 4 days after inoculation and remained steady until 5 days after inoculation. The highest enzymatic activity was observed at 6 days after inoculation with a value of $21.85 \mathrm{unit} / \mathrm{mL}$. A slight decrease in chitinase enzyme activity was observed at the final day of the incubation. 


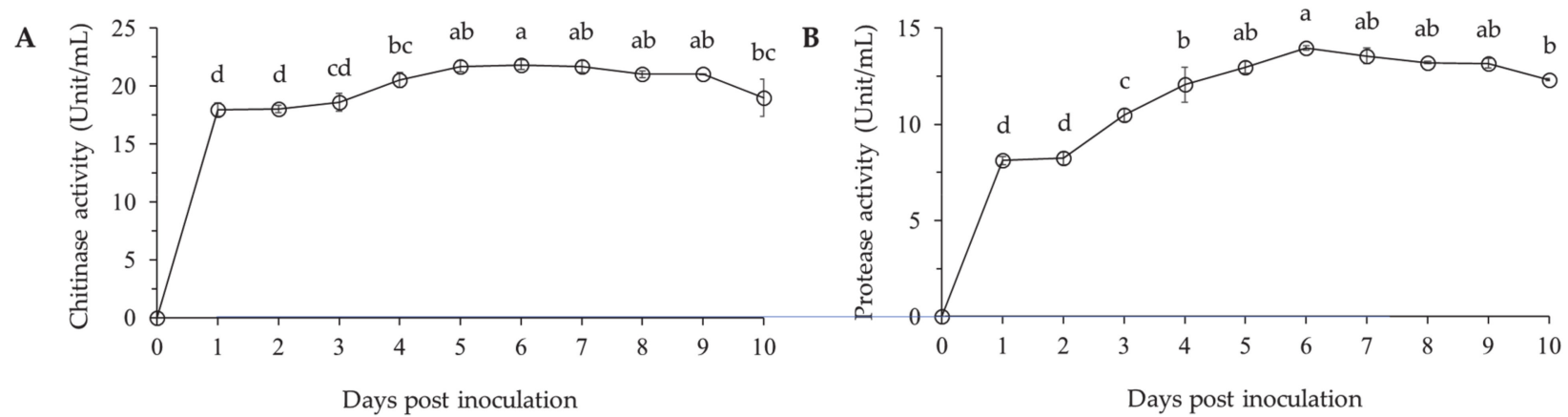

Figure 3. Chitinase (A) and protease (B) activity by Lysobacter antibioticus HS124 in CY medium. Values are represented as means \pm standard errors $(n=3)$. Different superscripts in the figure indicate significantly different values using Waller-Duncan test $(p<0.05)$.

The protease activity of L. antibioticus HS124 was stable in the first 2 days after inoculation and rapidly increased at 3 days after inoculation (Figure 3B). A continuous increase of protease activity was observed until 6 days after inoculation, reaching a maximum value of $13.99 \mathrm{unit} / \mathrm{mL}$. Subsequently, the activity decreased until the end of the incubation period.

Based on the bioinformatic analysis, 6 chitinase (or chitinase-like) and 29 protease genes were identified from L. antibioticus HS124 (Tables S1 and S2). The identified protease genes included 6 metalloproteases, 1 signal peptide peptidase, 4 ATP-dependent protease, 8 protease, and 10 serine protease genes. Interestingly, four of six chitinase genes included the signal peptide domain. Moreover, protease genes, which included the signal peptide domain, were mainly involved in the protease and serine protease groups.

\subsubsection{Hyphantria cunea Larvae Mortality of Lysobacter antibioticus HS124}

Treatment with crude enzymes and L. antibioticus HS124 bacteria culture with water $(1: 2 v / v)$ were highly effective to induce $H$. cunea larvae mortality in the laboratory (Figure 4). Treatment with crude enzymes showed relatively higher larvicidal activity against the H. cunea larvae, with up to $10.0 \%$ mortality, 2 days after application compared to bacteria culture treatment, which required longer time (4 days post-application) to induce mortality. The larvicidal effect of these crude enzymes increased with time (post-application days) and the highest mortality rate (76.6\%) was observed 9 days after treatment (Figure 4). Only 16.7\% larvae mortality rate was observed in the bacteria culture treatment after 5 days, but the rate increased 4 times to $66.7 \% 8$ days post-application. The time post-application had a significant effect on larvae mortality. In overall, the larvicidal activity of crude enzymes and bacteria culture were observed from 1 to 9 days and 4 to 8 days post-application, respectively. Crude enzyme treatment showed significantly higher efficacy than the bacteria culture (Figure 4). Moreover, treatment and post-application time interaction had a significant effect on larvae mortality. No significant difference was observed between control (water) and CY media and larvae mortality in both groups were only observed 7 days post-application. The maximum larvae mortality of $23.3 \%$ and $13.3 \%$ were observed in CY medium with water $(1: 2 v / v)$ and control (water) at 10 days post-application, respectively (Figure 4).

Foliar application of L. antibioticus HS124 culture on P. canadensis trees in the field experiment was conducted in an attempt to control the H. cunea larvae (Figure $1 \mathrm{C}(\mathrm{d}-\mathrm{e})$ ). $P$. canadensis trees treated with the bacterial culture little damage caused by the larvae on the leaves (Figure 1C(d)). Additionally, H. cunea larvae activity was rarely observed in the bacterial treatment group. However, in the control field, H. cunea larvae were spread throughout the leaves of the P. canadensis trees and innumerable webbings and larva exuviae formed on the trees as shown (Figure $1 \mathrm{C}(\mathrm{a}-\mathrm{b})$ ). The larvae feeding activity resulted in severe damage on $P$. canadensis trees, causing almost total defoliation as shown (Figure $1 \mathrm{C}(\mathrm{c})$ ). 


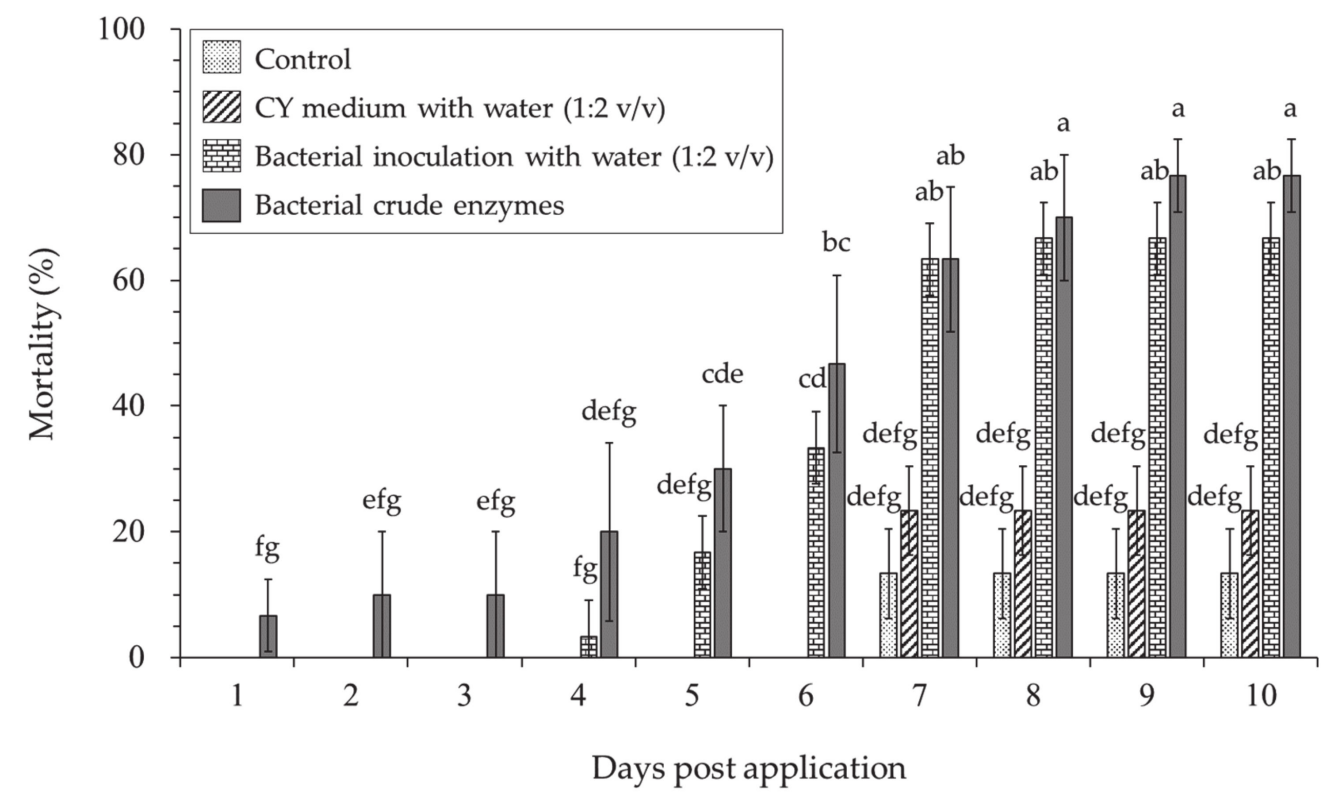

Figure 4. Average mortality rate of Hyphantria cunea larvae in control (distilled water), CY medium diluted with distilled water (1:2v/v), bacterial culture diluted with distilled water $(1: 2 v / v)$, and crude enzymes from Lysobacter antibioticus HS124 treatment in laboratory experiment. Error bars represent standard errors of the mean $(n=3)$ for each day. Means were separated by Waller-Duncan multiple range test. Means with different superscripts in the figure indicate significantly different values.

\subsubsection{Morphological Deformation of the Hyphantria cunea Larvae}

SEM analysis of dead larvae from the laboratory experiment revealed differences between treatments and control group (Figure 5A). The larvae cuticle of the dead larvae in the control (Figure 5A(a)) and CY media (Figure 5A(b)) showed normal morphologies without disruption or damage to the cuticle and setae. However, the morphological features of dead larvae from both the bacterial culture (Figure 5A(c)) and crude enzymes (Figure 5A(d)), showed abnormal morphologies, characterized by substantial loss of setae from the cuticles (indicated by the red arrows) and swelling of sockets at the base of setae, leading to complete rupture of the exoskeleton (yellow arrows).

Similarly, the cuticle of dead larvae collected from the field experiment displayed substantial differences between the control (Figure $5 \mathrm{~B}(\mathrm{a})$ ) and bacterial treatment (Figure $5 \mathrm{~B}(\mathrm{~b})$ ). The larvae cuticles in the treatment group showed broken setae (red arrows), with swollen sockets and ruptured cuticles (yellow arrows) while the control group displayed normal structure with setae and healthy cuticles.

\subsection{Promotion Effects of Lysobacter antibioticus HS124 on Growth of Populus canadensis}

\subsubsection{Indole-3-Acetic Acid Production of Lysobacter antibioticus HS124}

Lysobacter antibioticus HS124 produced auxin, IAA during growth (Figure 6). The IAA concentration steadily increased for 5 days, eventually reaching a maximum value of $3.8 \mathrm{mg} / \mathrm{mL}$ in 6 days. Thereafter, the IAA concentration decreased gradually. 
A
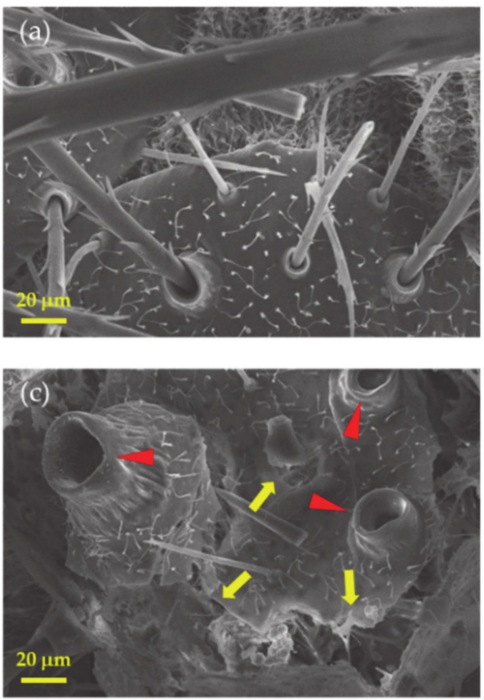

B

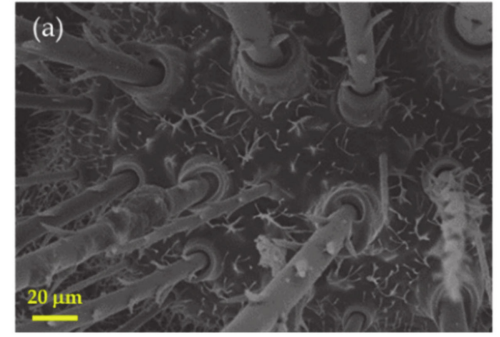

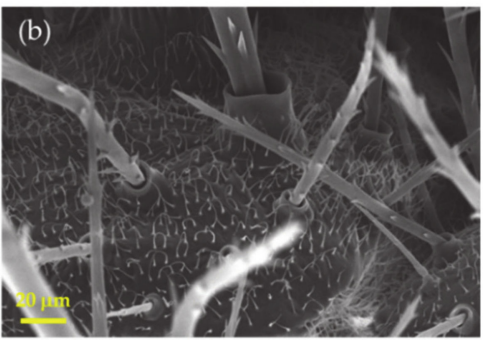
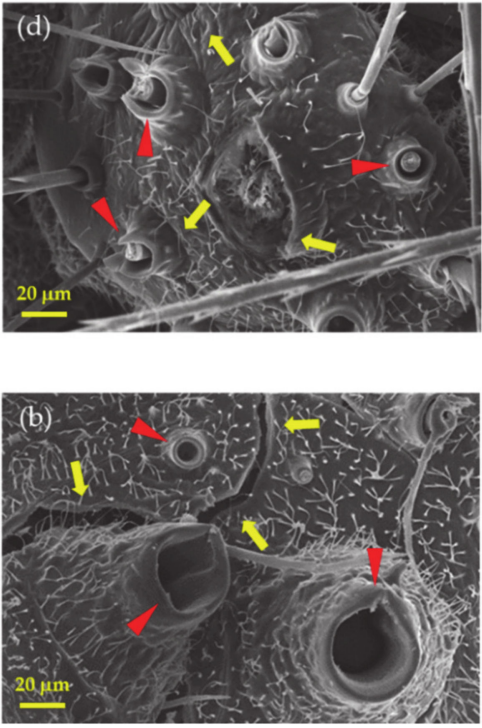

Figure 5. Exoskeletons of Hyphantria cunea larvae observed using SEM, the control (distilled water) (Aa), CY media diluted with distilled water (1:2 v/v) (Ab), bacterial culture diluted with distilled water $(1: 2 v / v)(\mathbf{c})$, and crude enzymes from Lysobacter antibioticus HS124 treatment (d) from the laboratory experiment (A). Normal structural in the control group (Ba) and bacterial culture diluted with tap water $(1: 2 v / v)(\mathbf{B b})$ from the field experiment $(\mathbf{B})$. Yellow arrows indicate the rupture of exoskeletons and red arrows indicate swollen sockets with damaged setae.

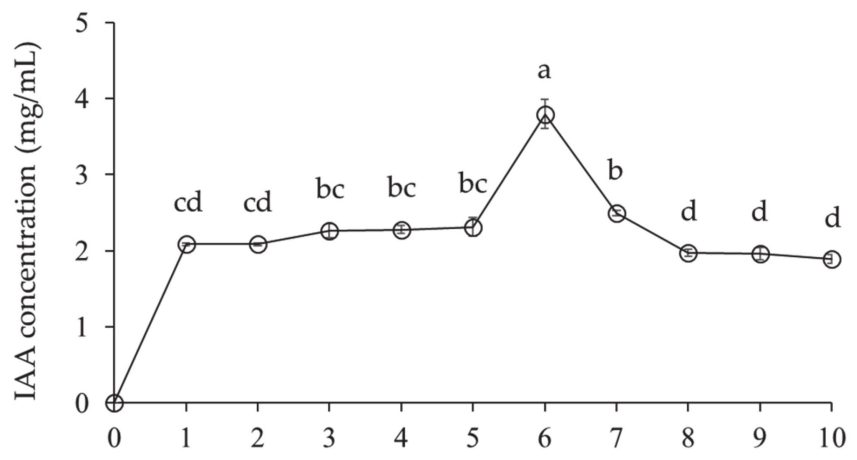

Figure 6. Indole-3-acetic acid production by Lysobacter antibioticus HS124. Values are represented as means \pm standard errors $(n=3)$. Different superscripts in the figure indicate significantly different values using Waller-Duncan test $(p<0.05)$.

\subsubsection{Growth and Biomass Yield of Populus canadensis Trees}

A significant increase in growth (root collar diameter and height) and biomass yield (leaf and stem dry weight) was observed in P. canadensis trees treated with the L. antibioticus HS124 culture compared to the control group (Table 1). When compared to the control group, treatment with L. antibioticus HS124 increased root collar diameter and tree height by 1.7- and 1.4-fold, respectively. Strikingly, the stem dry weight of the treatment group was 5.1-fold higher than that of the control group (Table 1). However, there were no leaves 
on P. canadensis trees in the control group due to severe defoliation under natural infestation by H. cunea larvae at the field (Table 1$)$.

Table 1. Growth and biomass production of Populus canadensis for the control vs Lysobacter antibioticus HS124 culture treatment in a coastal reclaimed land.

\begin{tabular}{|c|c|c|c|c|c|}
\hline \multirow{2}{*}{ Treatment } & \multicolumn{2}{|c|}{ Tree Growth (cm) } & \multicolumn{3}{|c|}{ Tree Biomass (kg) } \\
\hline & Root Collar Diameter & Height & Leaf Dry Weight & Stem Dry Weight & Total \\
\hline Control & $4.0 \pm 0.1 *$ & $444.4 \pm 13.0 *$ & $0.0 \pm 0.0 *$ & $0.9 \pm 0.1 *$ & $0.9 \pm 0.1 *$ \\
\hline $\begin{array}{c}\text { Lysobacter antibioticus } \\
\text { HS124 }\end{array}$ & $6.7 \pm 0.2 *$ & $604.4 \pm 21.9 *$ & $0.4 \pm 0.0 *$ & $4.5 \pm 0.3 *$ & $4.9 \pm 0.3^{*}$ \\
\hline$p$-value & 0.001 & 0.004 & $<0.001$ & $<0.001$ & $<0.001$ \\
\hline
\end{tabular}

Values are means \pm standard errors. ${ }^{*}$ Indicates a significant difference between means in the same column.

\section{Discussion}

\subsection{Larvicidal Activity of Lysobacter antibioticus HS124 against the Hyphantria cunea Larvae}

The cuticle-degrading chitinases and proteases used by entomopathogenic bacteria to penetrate insect structural barriers can be potentially useful in insect pest management. These enzymes weaken the structural defense system and thus increase the vulnerability of insect to external aggressions [20,39]. In the present study, L. antibioticus HS124 secreted cuticle-degrading chitinase and protease (Figure 3). Bioinformatic analysis indicated that there are 6 and 29 putatively secreting genes for chitinase and proteases, respectively (Tables S1 and S2). Especially, several chitinase glycoside hydrolase subfamily 18 (GH18) genes and serine protease genes were identified from L. antibioticus HS124 (Tables S1 and S2). GH18 chitinase is responsible for chitinase enzyme production, which then degrades chitin into low molecular weight of $\mathrm{N}$-acetylglucosamine such as chitotetraose, chitotriose, and chitobiose $[27,29]$. This leads to structural disintegration of vital insect organs such as the cuticle $[28,40]$, causing mortality of insect pests due to the hydrolytic activity in the larvae cuticles [28,41,42]. In addition, serine proteases have extensive primary specificity for amino acids (e.g., phenylalanine, methionine, and alanine) with a hydrophobic side group in the second carbon atom, but also has a secondary specificity for extended peptide chains with active sites recognizing at least five subsite residues [29]. Due to this comparative non-specificity, the general protease could have high hydrolytic activity on the insect exoskeleton by breaking down various proteins (casein, elastin, bovine serum albumin, and collagen) present in the larval cuticle [25,29]. These genes have indicated that $L$. antibioticus HS124 causes hydrolytic activity in the larvae cuticle and could potentially play an important role in insect pest management.

In laboratory experiments, the highest insecticidal activity of L. antibioticus HS124 crude enzyme and bacteria culture against $H$. cunea larvae was $76.6 \%$ and $66.7 \%$ at 10 days post application, respectively (Figure 4). Crude enzyme treatment showed higher efficacy, causing early mortality compared to bacterial culture (Figure 4). The slightly lower effect of bacteria culture compared to crude enzyme could be related to culture dilution $(1: 2 v / v$ with water). The larvae mortality was consistent with the rupturing of the outermost epicuticle (Figure 5A) which could be a result of increased stress caused by hydrolytic activity of cuticle-degrading enzymes. Treatment with L. antibioticus HS124 culture or crude enzymes caused a drastic morphological deformation of H. cunea larvae cuticles, causing swelling and rupturing of the exoskeleton (Figure 5A). Additionally, there was a pronounced loss of larval socketed setae (Figure 5A). The loss of socketed setae of H. cumea caused more stress, due to the physical impact on the epicuticle and water loss [24]. On the other hand, the mortality observed in the CY medium and control was only $23.3 \%$ and $13.3 \%$ after 10 days of treatment, respectively. Moreover, the cuticles of dead larvae in the CY media and control showed the normal shape of the larval socketed setae and cuticles. The disintegration of the larvae cuticle, deformation of socketed setae, and the subsequent larvae mortality in insects treated with a bacterial culture or crude enzyme suggests that the entomopathogenic bacterium L. antibioticus HS124 could be an effective biopesticide 
against $H$. cumea. Foliar application of L. antibioticus HS124 culture using a vehicle-mounted sprayer machine on $P$. canadensis trees in the field experiment resulted in a rapid decrease in larvae density and subsequent reduction in the level of leaf damage caused by H. cumea (Figure 1). Similarly, the cuticle of dead larvae in field experiments were also observed, and the larvae treated with bacterial cultures showed cuticle disruption and deformation of socketed setae (Figure 5B). In contrast, the cuticle of the dead larvae in the control group was found to have a normal morphology without degradation damage (Figure 5B). The activity of chitinase and protease from entomopathogenic bacteria against pests has been well documented at laboratory scale [20,21]. However, the efficacy of forest-scale application of bacterial culture containing cuticle-degrading enzymes, such as chitinase and protease, secreted by entomopathogenic bacteria remains unknown. Based on molecular and biochemical results of this study, the entomopathogenic bacterium L. antibioticus HS124 could be adopted as a biopesticide to control H. cunea on a large-scale forest setting.

\subsection{Promotion Effects of Lysobacter antibioticus HS124 on Growth of Populus canadensis}

The application of L. antibioticus HS124 culture resulted in significant growth promotion of $P$. canadensis trees through the control of pest activity and enhancement of the growth via phytohormones such as auxin. The P. canadensis cuttings in the control group grew to average of $4.0 \mathrm{~cm}$ in root collar diameter and $444.4 \mathrm{~cm}$ in height (Table 1$)$. With the foliar application of L. antibioticus HS124 culture, the root collar diameter and height of $P$. canadensis cuttings increased by 1.7- and 1.4-fold, respectively (Table 1). Compared to the total biomass $(0.9 \mathrm{~kg})$ in the control group, the $P$. canadensis cuttings treated with bacterial culture had a 5.4-fold increase in total biomass yield (Table 1). Since 2015, the P. canadensis plantations have suffered widespread defoliation due to $H$. cunea infestation, resulting in a serious decrease in biomass yields (Figure 1). Leaves are the major determinants of biomass productivity $[43,44]$. They play a crucial role in photosynthesis, thereby providing carbohydrates for other plant metabolic processes. Loss of leaf area reduces plant surface area for light absorption, which can significantly affect the photosynthetic rate and in turn reduce tree growth and biomass production [43]. Moreover, photosynthesis also plays a vital role in carbon sequestration, which is an important aspect of forest ecosystem and climate mitigation [43]. In this study, P. canadensis cuttings treated with L. antibioticus HS124 culture provided sufficient protection against the destructive phytophagous $H$. cunea larvae via cuticle-degrading enzymes such as chitinase and protease (Figures 1 and 3). Consequently, treatment with L. antibioticus HS124 prevented tree defoliation, thereby guaranteeing an adequate leaf surface and thus contributing to the high photosynthetic activity compared to the control group.

In addition, L. antibioticus HS124 produced the IAA phytohormone (Figure 6), which acts as a general coordinator of plant growth and development $[7,8,25]$. IAA is absorbed into leaves through foliar application, promoting biomass production through rapid growth such as shoot tissue emergence, shoot length extension, and young leaves development [31,45]. Then, IAA moves cell-to-cell transports from shoots to roots by polar auxin transport [45]. IAA enters plant cells by two interconnected transport systems: (1) the non-ionized protonated indole-3-acetamide hydrolase (IAAH), which is lipophilic and therefore enters the plant cell through the lipid bilayer by passive diffusion, and (2) anionic form IAA ${ }^{-}$, which enters into the cytoplasm by active co-transport by auxin influx carriers such as auxin-resistant/like aux (AUX/LAX) present in the cell membrane [46,47]. Once through the lipid bilayer into the cells, the molecules are exposed to a more basic $\mathrm{pH}$ within the cells and are almost completely dissociated to produce anionic IAA, which crosses the lipid bilayer to leave the cells $[46,47]$. Hence, IAA can be transported to the cell wall space only by the auxin efflux carriers, an active transport component in the plasma membrane [45-47]. Among the auxin efflux carriers, the downward transportation from shoot to the root occurs by pin-formed (PIN) proteins located only in the basement membrane (i.e., on their lower side) $[45,46]$. The IAA that reaches the roots causes root hair development and lateral root formation, thereby increasing the surface area of the root 
system in contact with the soil [33]. As a result, trees can absorb more water and mineral nutrients, thereby improving plant growth and biomass production [33]. Therefore, foliar application of IAA can greatly improve growth and biomass production in seedlings [30], which is also consistent with the results of the current study. In addition, exogenous auxin treatment triggers increased levels of endogenous auxin, thereby activating cambial growth, and the internal auxin acts as a growth regulator for the entire plant [30]. Therefore, L. antibioticus HS124 treatment increased plant growth and biomass of P. canandensis compared to the control (Table 1) due to IAA production (Figure 6).

\section{Conclusions}

Formulations of chitinases and proteases with other biopesticides or chemically synthesized pesticides might allow for a reduction in the environmental impact of toxic chemical compounds and reduce the risk of pesticide resistance. In addition, auxin improved the growth of poplar trees by promoting cell division, tissue growth, and lateral root initiation. In conclusion, this work sheds light on (i) the efficacy of investigations into biological pesticide development and use of biocontrol technologies as part of integrated pest management programs, and (ii) the need to develop unconventional heterologous platforms to initiate biomass production in large-scale forests. Microbial technology is crucial to the development of novel pesticides and sustainable biomass production. To the best of our knowledge, this is the first report on a forest-scale demonstration of simultaneous improvement in forest biomass production by controlling of forest pests with cuticle degrading enzymes such as chitinase and protease secreted by entomopathogenic bacteria and promotion of tree growth by phytohormone production.

Supplementary Materials: The following are available online at https:/ / www.mdpi.com/article/10 .3390 / microorganisms9081580/s1, Table S1: List of chitinase genes identified in the L. antibioticus HS124 genome. Table S2: List of protease genes identified in the L. antibioticus HS124 genome.

Author Contributions: Conceptualization, Y.S.A. and Y.H.J.; funding acquisition and project administration, Y.S.A.; investigation and experiments, J.-H.M., S.-J.W., C.E.H.M., J.-H.C. and S.-I.C.; data analysis, J.-H.M., S.-J.W., C.E.H.M. and Y.H.J.; original draft preparation, J.-H.M. and Y.S.A.; review and editing, J.-H.M., H.B.A., Y.S.A. and Y.H.J. All authors have read and agreed to the published version of the manuscript.

Funding: This study was supported by the R\&D program for Forest Science Technology (Project No. 2021376A00-2123-BD02) funded by the Korea Forest Service (Korea Forestry Promotion Institute). Additionally, this research was supported by a grant (Project No. 2018R1D1A1B07050052) from the National Research Foundation (NRF) of Korea under the Basic Science Research Program.

Institutional Review Board Statement: Not applicable.

Informed Consent Statement: Not applicable.

Data Availability Statement: Data available on request from the corresponding author.

Acknowledgments: The authors would like to thank Kil Yong Kim (Department of Agricultural and Biological Chemistry, Chonnam National University) for providing advice on the technology of entomopathogenic bacteria. The authors also extend the appreciation to Yun-Serk Park (Institute of Environmentally-Friendly Agriculture, Chonnam National University) for giving on-site fermenter training.

Conflicts of Interest: The authors have no conflicts of interest relevant to this study to disclose. The funders had no role in the design of the study; in the collection, analyses, or interpretation of data; in the writing of the manuscript; or in the decision to publish the results. 


\section{References}

1. Karp, A.; Shield, I. Bioenergy from plants and the sustainable yield challenge. New Phytol. 2008, 179, 15-32. [CrossRef] [PubMed]

2. Tian, X.; Sohngen, B.; Kim, J.B.; Ohrel, S.; Cole, J. Global climate change impacts on forests and markets. Environ. Res. Lett. 2016, 11, 035011. [CrossRef]

3. Wang, D.; LeBauer, D.; Dietze, M. Predicting yields of short-rotation hybrid poplar (Populus spp.) for the United States through model-data synthesis. Ecol. Appl. 2013, 23, 944-958. [CrossRef]

4. Mosquera-Losada, M.R.; Morán-Zuloaga, D.; Rigueiro-Rodriguez, A. Effects of lime and sewage sludge on soil, pasture production and tree growth in a six-year-old Populus canadensis Moench silvopastoral system. J. Plant. Nutr. Soil Sci. 2011, 174, 145-153. [CrossRef]

5. Rubio, A.; Loetti, V.; Bellocq, I. Effect of defoliation intensity and timing on the growth of Populus alba and Salix babylonica x Salix alba. Bosque 2013, 34, 353-358. [CrossRef]

6. Chen, S.; Hawighorst, P.; Sun, J.; Polle, A. Salt tolerance in Populus: Significance of stress signaling networks, mycorrhization and soil amendments for cellular and whole-plant nutrition. Environ. Exp. Bot. 2014, 107, 113-124. [CrossRef]

7. $\quad$ Park, H.-G.; Lee, Y.-S.; Kim, K.-Y.; Park, Y.-S.; Park, K.-H.; Han, T.-H.; Park, C.-M.; Ahn, Y.S. Inoculation with Bacillus licheniformis MH48 promotes nutrient uptake in seedlings of the ornamental plant Camellia japonica grown in Korean reclaimed coastal lands. Korean J. Hortic. Sci. Technol. 2017, 35, 11-20. [CrossRef]

8. Won, S.-J.; Kwon, J.-H.; Kim, D.-H.; Ahn, Y.-S. The effect of Bacillus licheniformis MH48 on control of foliar fungal diseases and growth promotion of Camellia oleifera seedlings in the coastal reclaimed land of Korea. Pathogens 2019, 8, 6. [CrossRef] [PubMed]

9. Jang, J.; Woo, S.Y.; Kwak, M.J.; Je, S.M.; Lee, J.K.; Kim, I.R. Evaluation of bioenergy potential and relative impact of microclimate conditions for sustainable fuel pellets production and carbon sequestration of short-rotation forestry (Populus $\times$ Canadensis Moench.) in reclaimed land, South Korea: Three-year monitoring. Sustainability 2020, 12, 6244. [CrossRef]

10. Cho, K.H.; Beon, M.-S.; Jeong, J.-C. Dynamics of soil salinity and vegetation in a reclaimed area in Saemangeum, Republic of Korea. Geoderma 2018, 321, 42-51. [CrossRef]

11. Edosa, T.T.; Jo, Y.H.; Keshavarz, M.; Anh, Y.S.; Noh, M.Y.; Han, Y.S. Current status of the management of fall webworm, Hyphantria cunea: Towards the integrated pest management development. J. Appl. Entomol. 2019, 143, 1-10. [CrossRef]

12. LaštůVka, Z. Climate change and its possible influence on the occurrence and importance of insect pests. Plant Prot. Sci. 2009, 45, S53-S62. [CrossRef]

13. Forestry Statistical Yearbook. Available online: https://www.forest.go.kr/kfsweb/cop/bbs/selectBoardArticle.do;jsessionid= CdQnCFhg3Ef0jHdTFpRAK9ZQsjaKK0nSirDxUlWiBCyILXm1JV6kPsv3PTPYXG2D.frswas02_servlet_engine5?nttId=31 22752\&bbsId=BBSMSTR_1064\&pageIndex=1\&pageUnit=10\&searchtitle=title\&searchcont=\&searchkey=\&searchwriter= \&searchdept=\&searchWrd=\&ctgryLrcls=\&ctgryMdcls=\&ctgrySmcls=\&ntcStartDt=\&ntcEndDt=\&orgId=\&mn=NKFS_04_05_ 09\&component $=$ (accessed on 5 October 2018).

14. Climate change scenario. Available online: http:/ / www.climate.go.kr/home/ (accessed on 20 October 2018).

15. Gill, H.K.; Garg, H. Pesticides: Environmental impacts and management strategies. In Pesticides-Toxic Aspects; Solenski, S., Larramenday, M.L., Eds.; InTech: Rijeka, Croatia, 2014; pp. 188-230. [CrossRef]

16. Mahmood, I.; Imadi, S.R.; Shazadi, K.; Gul, A.; Hakeem, K.R. Effects of pesticides on environment, In Plant, Soil and Microbes, Hakeem, K.R.; Akhtar, M.S., Abdullah, S.N.A., Eds.; Springer International Publishing: Cham, Switzerland, 2016; pp. 253-269. [CrossRef]

17. Nicolopoulou-Stamati, P.; Maipas, S.; Kotampasi, C.; Stamatis, P.; Hens, L. Chemical pesticides and human health: The urgent need for a new concept in agriculture. Front. Public Health 2016, 4, 148. [CrossRef]

18. Ruiu, L. Insect pathogenic bacteria in integrated pest management. Insects 2015, 6, 352-367. [CrossRef] [PubMed]

19. Yang, Z.-Q.; Wei, J.-R.; Wang, X.-Y. Mass rearing and augmentative releases of the native parasitoid Chouioia cunea for biological control of the introduced fall webworm Hyphantria cunea in China. Biocontrol 2006, 51, 401-418. [CrossRef]

20. Kramer, K.J.; Muthukrishnan, S. Insect chitinases: Molecular biology and potential use as biopesticides. Insect Biochem. Mol. Biol. 1997, 27, 887-900. [CrossRef]

21. Berini, F.; Casartelli, M.; Montali, A.; Reguzzoni, M.; Tettamanti, G.; Marinelli, F. Metagenome-sourced microbial chitinases as potential insecticide proteins. Front. Microbiol. 2019, 10, 1358. [CrossRef] [PubMed]

22. Koul, O. Microbial biopesticides: Opportunities and challenges. CAB Rev. Perspect. Agric. Veterinary. Sci. Nutr. Nat. Resour. 2012, 6, 56. [CrossRef]

23. Ferré, J.; Van Rie, J. Biochemistry and genetics of insect resistance to Bacillus thuringiensis. Annu. Rev. Entomol. 2002, 47, 501-533. [CrossRef]

24. Merzendorfer, H.; Zimoch, L. Chitin metabolism in insects: Structure, function and regulation of chitin synthases and chitinases. J. Exp. Biol. 2003, 206, 4393-4412. [CrossRef]

25. Dong, Z.; Zhang, W.; Zhang, Y.; Zhang, X.; Zhao, P.; Xia, Q. Identification and characterization of novel chitin-binding proteins from the larval cuticle of silkworm, Bombyx mori. J. Proteome Res. 2016, 15, 1435-1445. [CrossRef]

26. Harrison, R.L.; Bonning, B.C. Proteases as insecticidal agents. Toxins 2010, 2, 935-953. [CrossRef] [PubMed]

27. Berini, F.; Katz, C.; Gruzdev, N.; Casartelli, M.; Tettamanti, G.; Marinelli, F. Microbial and viral chitinases: Attractive biopesticides for integrated pest management. Biotechnol. Adv. 2018, 36, 818-838. [CrossRef] [PubMed]

28. Charnley, A.K. Fungal pathogens of insects: Cuticle degrading enzymes and toxins. Adv. Bot. Res. 2003, 40, 241-321. [CrossRef] 
29. Ali, S.; Huang, Z.; Ren, S. Production of cuticle degrading enzymes by Isaria fumosorosea and their evaluation as a biocontrol agent against diamondback moth. J. Pestic. Sci. 2010, 83, 361-370. [CrossRef]

30. Xu, Y.; Zhang, Y.; Li, Y.; Li, G.; Liu, D.; Zhao, M.; Cai, N. Growth promotion of Yunnan pine early seedlings in response to foliar application of IAA and IBA. Int. J. Mol. Sci. 2012, 13, 6507-6520. [CrossRef] [PubMed]

31. Kwon, J.-H.; Won, S.-J.; Moon, J.-H.; Kim, C.-W.; Ahn, Y.-S. Control of fungal diseases and increase in yields of a cultivated jujube fruit (Zizyphus jujuba Miller var. inermis Rehder) orchard by employing Lysobacter antibioticus HS124. Forests 2019, $10,1146$. [CrossRef]

32. Moon, J.-H.; Won, S.-J.; Maung, C.E.H.; Choi, J.-H.; Choi, S.-I.; Ajuna, H.B.; Ahn, Y.S. Bacillus velezensis CE 100 inhibits root rot diseases (Phytophthora spp.) and promotes growth of Japanese cypress (Chamaecyparis obtusa Endlicher) seedlings. Microorganisms 2021, 9, 821. [CrossRef]

33. Al-haidary, H.K.M.A.; Abd AL-hassan, S. Foliar application of IAA at different growth stages and their influenced on growth and productivity of bread Wheat (Triticum aestivum L.). J. Phys. Conf. Ser. 2019, 1294, 092029. [CrossRef]

34. Kang, S.-J.; Lee, Y.-S.; Lee, S.-Y.; Yun, G.-Y.; Hong, S.-H.; Park, Y.-S.; Kim, I.-S.; Park, R.-D.; Kim, K.-Y. Biological control of diamondback moth (Plutella xylostella L.) by Lysobacter antibioticus HS124. Korean J. Soil. Sci. Fert. 2010, 43, 659-666.

35. Lingappa, Y. Chitin media for selective isolation and culture of actinomycetes. Phytopathology 1962, 52, 317-323. [CrossRef]

36. Ghorbel-Frikha, B.; Sellami-Kamoun, A.; Fakhfakh, N.; Haddar, A.; Manni, L.; Nasri, M. Production and purification of a calcium-dependent protease from Bacillus cereus BG1. J. Ind. Microbiol. Biotechnol. 2005, 32, 186-194. [CrossRef]

37. Bradford, M.M. A rapid and sensitive method for the quantitation of microgram quantities of protein utilizing the principle of protein-dye binding. Anal. Biochem. 1976, 72, 248-254. [CrossRef]

38. Rahman, A.; Sitepu, I.R.; Tang, S.-Y.; Hashidoko, Y. Salkowski's reagent test as a primary screening index for functionalities of rhizobacteria isolated from wild dipterocarp saplings growing naturally on medium-strongly acidic tropical peat soil. Biosci. Biotechnol. Biochem. 2010, 74, 2202-2208. [CrossRef]

39. Nakahara, Y.; Watanabe, M.; Fujita, A.; Kanamori, Y.; Tanaka, D.; Iwata, K.-I.; Furuki, T.; Sakurai, M.; Kikawada, T.; Okuda, T. Effects of dehydration rate on physiological responses and survival after rehydration in larvae of the anhydrobiotic chironomid. J. Insect Physiol. 2008, 54, 1220-1225. [CrossRef] [PubMed]

40. Suzuki, K.; Sugawara, N.; Suzuki, M.; Uchiyama, T.; Katouno, F.; Nikaidou, N.; Watanabe, T. Chitinases A, B and C1 of Serratia marcescens 2170 produced by recombinant Escherichia coli: Enzymatic properties and synergism on chitin degradation. Biosci. Biotechnol. Biochem. 2002, 66, 1075-1083. [CrossRef]

41. Han, Y.; Taylor, E.B.; Luthe, D. Maize Endochitinase Expression in Response to Fall Armyworm Herbivory. J. Chem. Ecol. 2021, 1-18. [CrossRef]

42. Chen, W.; Qu, M.; Zhou, Y.; Yang, Q. Structural analysis of group II chitinase (ChtII) catalysis completes the puzzle of chitin hydrolysis in insects. J. Biol. Chem. 2018, 293, 2652-2660. [CrossRef] [PubMed]

43. Anten, N.P.R.; Ackerly, D.D.A. new method of growth analysis for plants that experience periodic losses of leaf mass. Funct. Ecol. 2001, 15, 804-811. [CrossRef]

44. Wan, S.; Xia, J.; Liu, W.; Niu, S. Photosynthetic overcompensation under nocturnal warming enhances grassland carbon sequestration. Ecology 2009, 90, 2700-2710. [CrossRef] [PubMed]

45. Adamowski, M.; Friml, J. PIN-dependent auxin transport: Action, regulation and evolution. Plant Cell 2015, 27, 20-32. [CrossRef] [PubMed]

46. Zažímalová, E.; Murphy, A.S.; Yang, H.; Hoyerová, K.; Hošek, P. Auxin transporters-why so many? Cold Spring Harb. Perspect. Biol. 2010, 2, a001552. [CrossRef] [PubMed]

47. Swarup, R.; Péret, B. AUX/LAX family of auxin influx carriers-an overview. Front. Plant Sci. 2012, 3, 225. [CrossRef] [PubMed] 